\title{
Material Culture of the Lepcha, Inhabitants of Sikkim, India: An Anthropological Perspective
}

\author{
Akash Deep \\ Research scholar \\ Department of Anthropology, Ranchi University, Ranchi, India
}

\begin{abstract}
Lepchas are the original inhabitants of Sikkim, India. The Lepchas are of mongoloid stock and some anthropologist trace their origins to Mongolia or Tibet. However, the Lepchas themselves have no such history of migration in their traditional knowledge. They believe themselves to be the natives of the Sikkim and even consider Mt. Kanchenjunga as the abode of their ancestors. This study is based on Material culture of the Lepcha. Material culture is tangible and ponderable object produced or used by humans like clothes, ornament, kitchen utensils, tools, machineries. Aim of this study is to know the material culture of Lepcha people and to know what are the changes coming in their material culture along with cause and effect of such changes. In this paper it will be further revealed that traditional material culture used by Lepcha people are vanishing gradually. Material culture are surviving in their society just as an antique souvenir of the past. Though there are also some types of material culture which are still in use. Due to various reasons mainly due to contact with other culture we can see change in their traditional culture materials.Tourism, modernization, acculturation are some reasons for change.
\end{abstract}

Key words: Material culture, Tangible, Change, Modernization, Acculturation.

\subsection{INTRODUCTION}

Material culture refers to the physical objects, resources, and spaces that people use to define their culture. These include clothes, ornament, kitchen utensils, tools, machineries etc. Lepchas are the original inhabitants of Sikkim. The Lepchas are of mongoloid stock and some anthropologist trace their origins to Mongolia or Tibet. However, the Lepchas themselves have no such history of migration in their traditional knowledge. They believe themselves to be the natives of the Sikkim and even consider Mt. Kanchenjunga as the abode of their ancestors.

\subsection{Lepcha people}

Lepchas are the original inhabitants of Sikkim, formerly an independent kingdom situated in the Himalayas between Nepal and Bhutan. Lepcha is the name given to this group by their Nepali neighbors and is interpreted by some as a derogatory word meaning "nonsense talkers." The Lepchas call themselves Rong.

The Lepchas are of Mongoloid stock, and some anthropologists trace their origins to Mongolia or Tibet. However, the people themselves have no traditions of past migrations and place the home of their ancestors (Mayel) near Mt. Kanchenjunga. The early history of the Lepchas is obscure, their isolation no doubt limiting contacts with the outside world. The Bhutias began moving into the region from Tibet in the 14th century ad. Sometime before the beginning of the 17th century, Sikkim became subject to Tibet. Internal upheavals in Tibet early in the 17th century led to three "Red Hat" lamas (monks) fleeing to Sikkim, where they converted the population to Buddhism and created a Sikkimese Tibetan king. For the next three centuries, the Lepchas of Sikkim were dominated by the Bhutias, the Nepalese, and later the British. In 1950, although it remained independent under its ruling chogyal (king), Sikkim became a protectorate of India. Following a plebiscite in which Hindu immigrants from India made the difference in the voting, Sikkim became the twenty-second state of the Indian union in 1975.

\subsection{Nomenclature}

The name 'Lepcha' is an exonym given by outsiders; in this case it is commonly believed to have derived from the Nepali words lap and che, which is supposed to mean 'vile speakers', 


\subsection{RESEARCH METHODOLOGY}

\subsection{Area of the study}

For field work on "Material Culture of the Lepcha" Ranka village in Gangtok (East district) Sikkim was selected.

According to Census 2011 information the village code of Ranka village is 261294. Ranka village is located in Gangtok Tehsil of East District in Sikkim, India. It is situated 16km away from Gangtok, which is both district \& sub-district headquarter of Ranka village. The total geographical area of village is 136.75 hectares. Ranka has a total population of 609 peoples. There are about 135 houses in Ranka village. Gangtok is nearest town to Ranka which is approximately $16 \mathrm{~km}$ away.

2.2 Sampling method- Unit of the study is selected through convenient \& Accidental sampling method. 30 Lepcha houses in Ranka village were selected for this study.

2.3 Unit of study-Target population was from all age and sex group. 60 informants and 5 key informants were interviewed.

2.4 Techniques of data collection

For the study the collection of primary data was done through following technique: -

2.4.1 Participant observation - Through Participant observation technique observations were made to understand their material culture.

2.4.2 Interview - Through interview technique data on material culture were collected. This also helped in rapport building. Two types of interview technique were used. Un-structured interview, Group interview

2.4.3 Schedule - With the help of schedule several data about their material culture were collected.

2.4.4 Photography - Through photography technique many pictures were taken related to my topic.

\subsection{FINDINGS}

3.1 House - Lepcha traditional house is called "Li". It is rectangular in structure with slopy roof. Which is made up of wood \& straw. They don't use any iron nails and the house were built only from wood they have a special technique of attaching wood in one another, but now they are also using nails to attached wood . the body and the floor is made of wood and the floor is raised $1 \mathrm{~m}$ or more above the ground. the space underneath is used to keep domestic animals.

3.2 Dress-The traditional clothing for Lepcha women is the ankle-length dumdyam or gada. It is one large piece of smooth cotton or silk, usually of a solid color. When it is worn, it is folded over one shoulder, pinned at the other shoulder, and held in place by a tago(waist band), over which excess material drapes. A long-sleeved blouse may be worn underneath. The traditional Lepcha clothing for men is the dumpra. It is a multicolored, hand-woven cloth pinned at one shoulder and held in place by a waistband, usually worn over white shirt and trousers. Men wear a flat round cap called a thyaktuk, the traditional coneshaped bamboo hats are worn. 
International Journal of Research in Social Science and Humanities (IJRSS), Vol .1(4), Sep-Oct- 2020

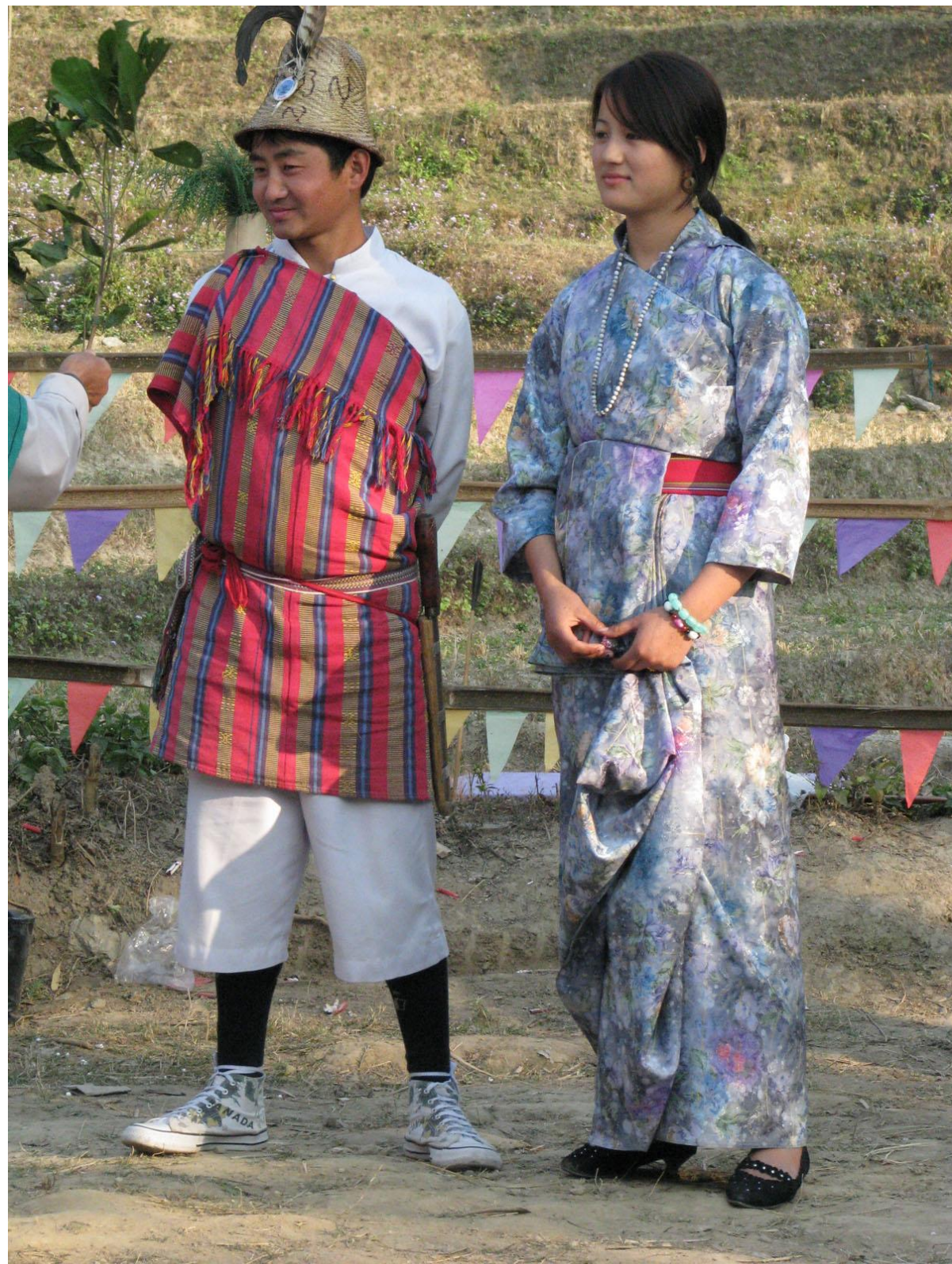

(Traditional lepcha dress )

Source:Internet

\subsection{House hold material}

3.3.1 Dalo: A bamboo container (Tokri)

Size- large in size

Material used -Dalo is made up of bamboo, it is hand made.

Use- use to contain things like fruits vegetables etc. 
International Journal of Research in Social Science and Humanities (IJRSS), Vol .1(4), Sep-Oct- 2020

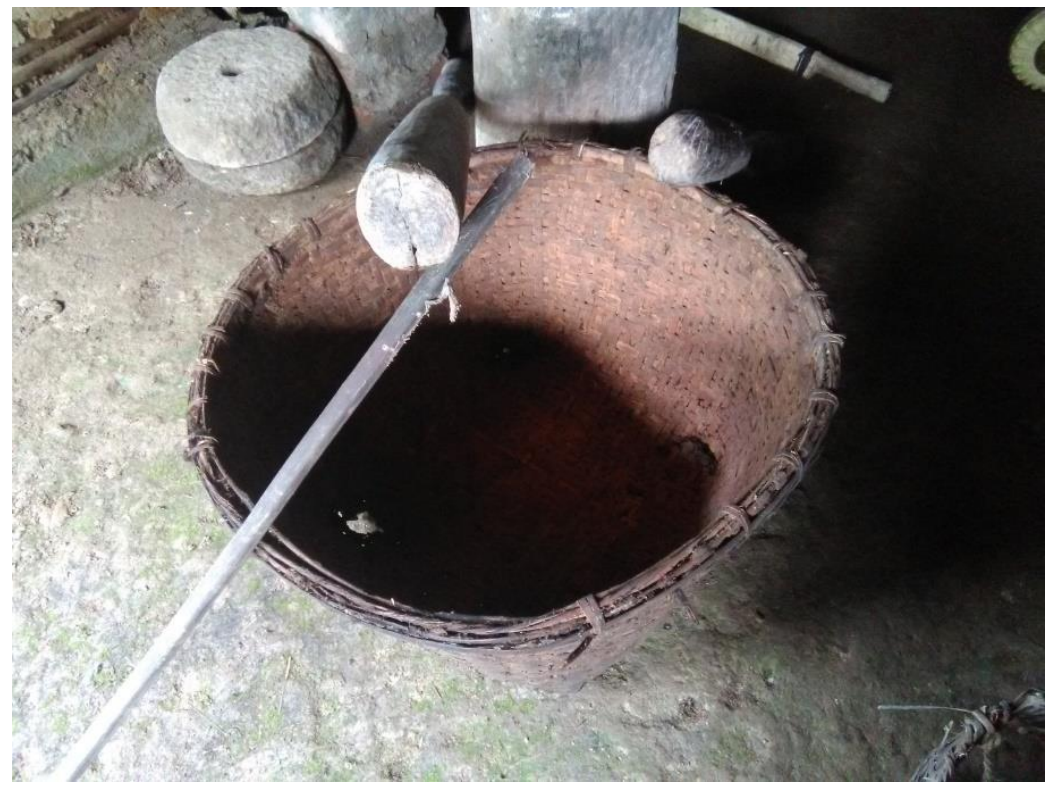

(Dalo)

Source- Fieldwork

3.3.2 Taling and Takcham- Pestle \& Mortar (khalbatta \& okhli)

Size - large in size

Material used - Both Taling and Takcham are made of of wood Use - It is used for grinding and mixing .

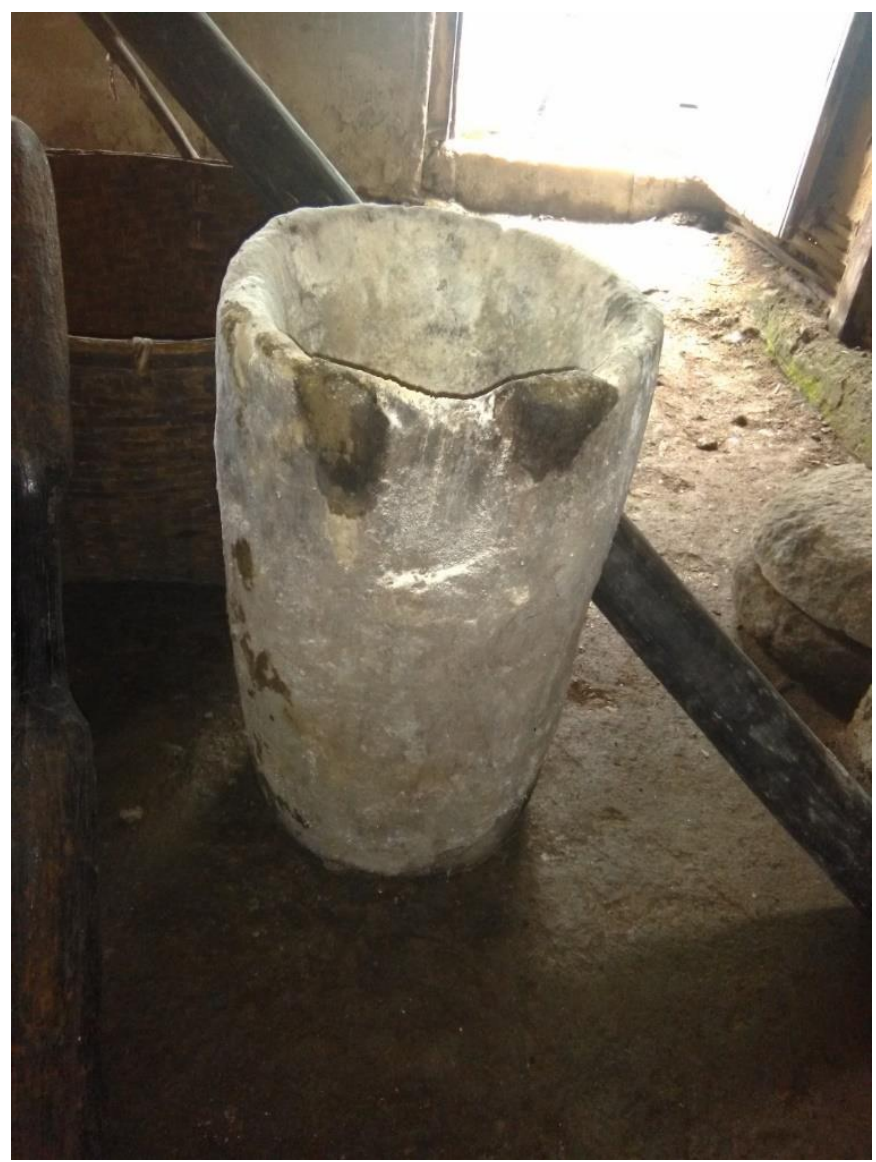

(Taling and Takcham)

Source- Fieldwork 


\subsubsection{Runtuck - (Chakki)}

Size- medium size

Material used- stone (quernstone)

Use- Runtuck is use to make flour . and to gring other things like pulse , wheat, millet,corn etc

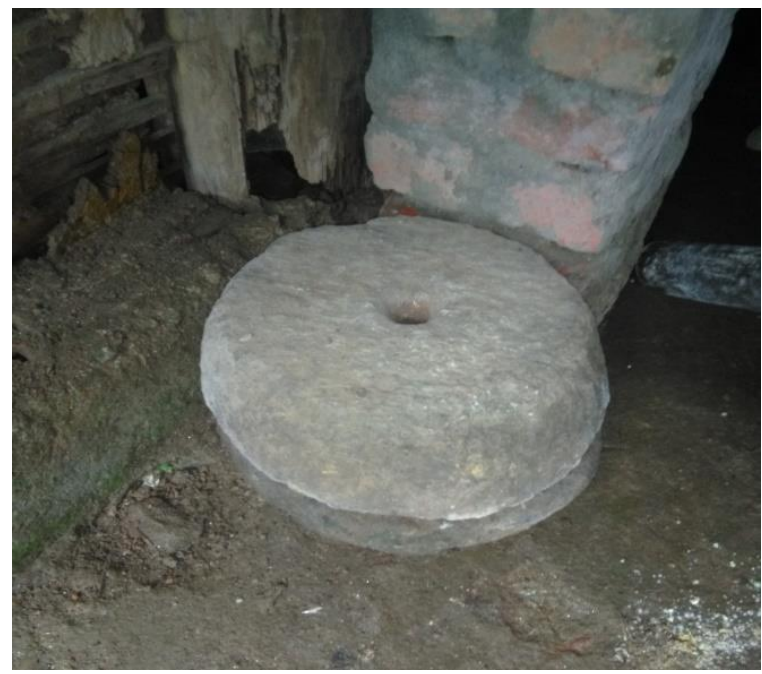

(Runtuck) Source- Fieldwork

\subsection{Hunting and Fishing}

3.4.1 Bampok - A knife Size - medium

Material used - iron and wood. The working end is made up of iron and the handle is made of wood.Use - to cut and to hunt.

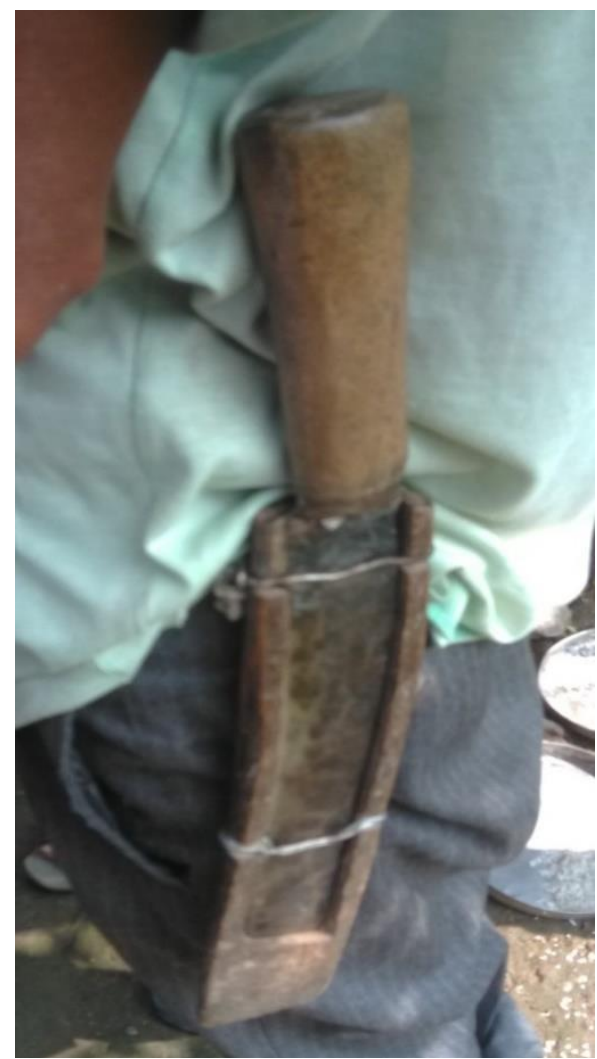

(Bampok)

Source- Fieldwork 


\subsubsection{Chongsili : Spear (bhala)}

Size- long in size. Material use- wood . and now we can also see use of iron.The body of the spear is made up of wood and pointed head is made up of iron.Use to hunt animals like bear, dear etc.

\subsubsection{Chowg Sikli : Bow and Arrow (Tir Dhanus)}

Material used - bamboo and iron . the Sikli (bow) is made up of bamboo and the Chowg (arrow) is made up of bamboo stick and a pointed iron head. Use to hunt animal from long distance.

3.3.4.Tuksur : Fishing net made up of bamboo.

Material used - bamboo. Use - for fishing . Procedure- a big rectangular shape bamboo net is made through bamboo and is places in river where waters flow is high in this water goes from the open end and with the water fish also get inside and the other end is closed water easily comes out from the bamboo net but the fish get traped inside.

\subsection{Musical instrument:}

3.5.1. Nyi- Bryaok- (Double barrel flute) Material used- Bamboo and thread. Use - this is played while welcoming someone special. Or played when sending someone special guest.

3.5.2. Tung Buk- (a three string musical instrument) Material used - wood and strings. It looks like small violin with 3 string and it is played like bass guitar.

3.5.3.Bom-Phathyoot - (bamboo whistle )Size- Small Material used -bamboo. Use - used as a whistle and to give signal in jungle .

\subsection{Handloom weaving:}

The handloom tradition in Sikkim is very old and Lepchas women play a predominant role in handloom weaving, they begin to learn the art from a very young age and gain exceptional craftsmanship in weaving intricately colorful fabrics from cotton yarn . For weaving, first of all, the cotton yarn is sent for winding in wooden frames according to the specified length and breadth requirement. The wound cotton yarn is then fitted in the vertical frame loom and weaving begins. The handloom products range from plain to intricate patterns. The mostly used colures are white, red, black, yellow and green. From the woven fabric variety of items, such as Lepcha traditional dresses, shoulder bags cushion cover, napkins and table mats, etc. are made.

3.6.1 Carpet weaving: The carpet weaving is done by Bhutia women. For carpet weaving, first of all the taan is made from cotton yarn according to the sizes. Then the weaving process begins according to the design, which is drawn on graph paper. While the weaving process goes on wooden hammers called flag are used to beat the woven wool into place. After the weaving is over, leveling is done with a leveling scissor to make the carpet thinner. Finally, the scissoring is done and the carpets are ready, which are used for covering sofas, beds, walls, chairs, etc.

\subsubsection{Blanket weaving}

The blanket weaving is done by Nepalese women. The blankets are normally woven with sheep wool. For weaving, first of all, raw wool is washed with soap to remove all dirt and is sun-dried; raw wool is brushed with carder brush for 2-3 days. The next process is spinning the yarn out of raw wool, which takes quite some time. A wooden instrument called, the phang is required to hold the yarn, which is done manually by hands. After the spinning process is over, the yarn is given colour. Chemical dyes or natural dyes like walnut bark, majito, shungey, etc. are used to produce different colour. Finally, in the weaving process, yarn of different shades is used and the taan or the main support for the weave is inserted to the iron steel reeds on the loom. The dyed woolen yarn is then ready to be woven into the blankets according to design.

\subsubsection{Thanka painting}

The thankas are the religious scrolls found hung in monasteries and houses of Buddhists. These are basically life sketches of Lord Buddha, Goddess Doma (Tara), or Guru Padmasambhava. A thanka serves as an ostensible symbol of the deity worshipped by the devotee, and it provides focal points for meditation. The thankas are painted by religious artisans known as Lharips. For thanka painting, first of all a rough piece of cotton is stretched on a frame and it is made smooth by sizing it with a mixture of chalk and glue. After it is dried and polished, painting is drawn on this cloth. Stone colour, vegetable dyes and two primary colours such as red and yellow are used in plenty while making a thanka painting. These two primary colures show the difference 
between fire and life, between material and immaterial. The orange symbolizes knowledge of the highest form of spirituality, the blue colour suggests depth, purity and infinity, while green represent the vegetable aspects.

\subsubsection{Wood carving}

Wood carving is an ancient art form of both the Lepchas and the Bhutias of Sikkim. The main raw material used in this craft is wood. The wood of Cedrela toona Roxb, (tooni), Juglans regia Linn. (okhar), and Michelia champaca Linn. (chap) are normally used for wood carving For wood carving, a piece of wood is cut into the desired shape at first. After seasoning process, very fine chisels and tools are used to curve out the designs. The carved pieces are then assembled together and get ready for a coat or paint. Chokse (folding table), bagschok (centre table), table lamp, sofa seats, screen partition etc. are major wood carved products of Sikkim .

\subsubsection{Wooden mask making}

Mask making is another ancient craft in Sikkim ${ }^{4}$. Wooden masks may depict serene, partly angry or anomaly expression. The masks are carved out of the tough light wood of Abies spectabilis (D.Don) Mirb. Prior to carving, the wood has to be seasoned. The wood piece is cut horizontally according to the size of the masks to be made. Thereafter, curved knife is used to bring to shape the concave and convex portions. The surface of the mask is smoothened by using sand paper, synthetic painting follows thereafter. Lucky sign are also made out of wood.

\subsubsection{Bamboo and cane craft}

Bamboo and cane craft are deep rooted in traditional culture of all three ethnic group of Sikkim. Various attractive ecofriendly products are made out of bamboo and cane, such as Lepcha hats, fruit and vegetable baskets, mugs, flower vases, tea trays, carry bags, containers, baskets, dustbins, mats.

\section{CONCLUSION}

This study was focused on the material aspects of culture of Lepcha's in Ranka village, Sikkim. It deals with general introduction of Lepcha, research methodology used, and all the material aspects of culture of Lepcha. Even though Lepcha has succeeded to conserve their culture but due to impact of modernization and cultural interaction their culture is being undergoing minor changes, which can be observed in their style of living, form of architecture, clothing, change in the traditional wares and tools. As their culture is still in transitional phase which can be well documented if tried hence Lepchas being the native tribe of Sikkim, their traditional culture needs to be preserved and documented. Further this study further highlighted the pattern of changes occurring in their material culture like those elements which always have been used in sustaining their economy has maintained their utility as their agricultural economy has been effect with drastic changes, hence some of their age-old tools are still in use. But with other material aspects of culture this is not true, like their musical instruments which are no longer being used by them and we can find it in few homes being kept as a souvenir of their past culture. So similarly, several of their traditional tools, instruments, clothing material has lost their utility due to impact of modernization, westernization and tourism. Then there are other items which now can be called as their cultural survivals. And again, this further opens up a new avenue for research in material culture studies, the study of cultural survivals which for sure will reflect their long rich history.

\section{REFERENCES}

Foning, A. R., 1987: “Lepcha: My Vanishing Tribe”, Sterling Publishers, University of Michigan.

Gorer, G., 1996: “The Lepchas of Sikkim”, Gyan Publishing House.

Lee, E. \& Marco Vivarelli,2006: “The Social Impact of Globalization in the Developing Countries”.

Reid, G.D.,2003: “Tourism, Globalization And Development: Responsible Tourism Planning”, Pluto Press, University of Michigan.

Tamsang, K.P., 1998: “The Unknown and Untold Reality about the Lepchas”, University of Michigan.

Thakur, R., 1988: “Himalayan Lepchas”, Archives Publishers, University of Michigan. 